06

\title{
Деформация и разрушение корундовой керамики с многоуровневой поровой структурой
}

\author{
(C) М.В. Григорьев, ${ }^{1}$, А.Г. Бурлаченко, ${ }^{1}$, С.П. Буякова, ${ }^{1,2,3}$, С.Н. Кульков ${ }^{1,2,3}$ \\ ${ }^{1}$ Институт фозики прочности и материаловедения СО РАН, \\ 634055 Томск, Россия \\ ${ }^{2}$ Национальный исследовательский Томский политехнический университет, \\ 634050 Томск, Россия \\ ${ }^{3}$ Национальный исследовательский Томский государственный университет, \\ 634050 Томск, Россия \\ e-mail: grv@ispms.ru
}

Поступило в Редакцию 29 июня 2018г.

В окончательной редакции 4 февраля 2019г.

Принято к публикации 5 июня 2019 г.

Изучено поведение при сжатии керамики $\mathrm{Al}_{2} \mathrm{O}_{3}$ с объемом порового пространства 50\%. Поровая структура, включала в себя поры трех видов: крупную пористость со средним размером 120 m, мелкую пористость со средним размером $2 \mu \mathrm{m}$ и протяженных (около $150 \mu \mathrm{m}$ ) поровых каналов, образованных в результате зонального обособления при спекании. Показано, что при нагружении керамики с подобной многоуровневой поровой структурой происходит накопление микроповреждений по всему объему образца, что обусловливает понижение масштабного уровня разрушения от макроскопического, в случае керамики с унимодальной поровой структурой, до мезо- и микромасштабного в керамике с многоуровневой поровой структурой. Остаточная деформация в таком материале появляется уже при малых нагрузках около $0.3 \sigma_{c}$ вследствие смещения блоков и их групп в ходе деформации задолго до предела прочности.

Ключевые слова: корундовая керамика, многоуровневая поровая структура, не упругое деформационное поведение, блочная структура.

DOI: 10.21883/JTF.2019.12.48489.255-18

\section{Введение}

Деформационное поведение пористых керамик в настоящее время детально изучено в основном для систем с унимодальной пористостью и относительно узким распределением пор по размерам [1-7]. Показано, что существуют пороговые значения объема порового пространства для таких материалов, при которых существенно изменяется как характер деформирования, так и последующее разрушение. Например, в [4] показано, что возможно проявление механизма микромеханической неустойчивости сформированных при спекании стержневых или ячеистых структур. При этом исследование эволюции повреждений в объеме подобных хрупких материалов представляет значительный интерес с точки зрения возникновения особых структур деформации и последующего разрушения. Кроме того, показано [3-6], что на характер деформации влияет и средний размер пор.

Поведение высокопористой керамики включает в себя, помимо упругой области при низких напряжениях, относительно обширную область неупругой деформации, обусловленную процессами зарождения и распространения микротрещин [2], а также накоплением микроповреждений вследствие разрушения стенок между порами и перемещение локальных объемов материала в поровое пространство $[1,2,4]$.
При создании пористых керамических материалов перспективным направлением считается синтез керамик с многоуровневой поровой структурой, имеющей различную конфигурацию - ячейки, каналы, и др. [1]. Подобные элементы структуры могут обеспечить особый характер деформирования пористого материала по сравнению с традиционными хрупкими материалами [1]. Тем не менее подобных исследований явно недостаточно ввиду сложности получения таких систем.

При спекании керамик формируется система пор с размерами, соизмеримыми с размерами зерна, либо при введении порообразователей - пор с размерами, определяемыми частицами порообразователя.

С другой стороны, известен эффект „зонального обособления“ вследствие активной усадки образцов при спекании [8], когда происходит разделение спекаемого образца на области, значительно превышающие средний размер частиц спекаемого материала. Характерно, что при этом возможно формирование нескольких видов поровой структуры, обусловленной межчастичной пористостью, крупной пористостью вследствие введения порообразователя и межблочной пористостью сформированной при зональном обособлении [9].

Целью настоящей работы является изучение особенностей деформационного поведения при квазистатическом сжатии корундовой керамики с многоуровневой поровой структурой. 

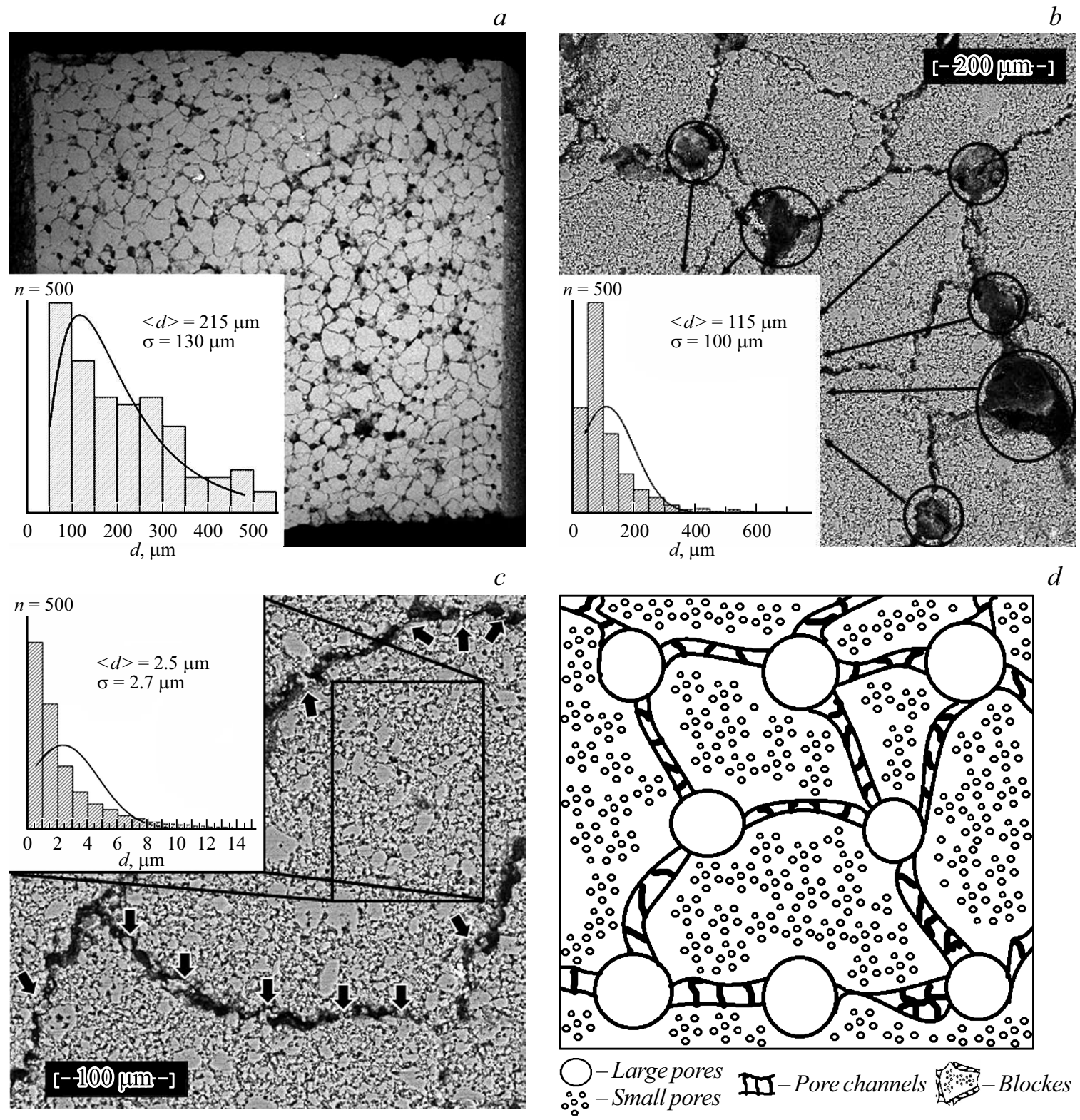

Рис. 1. $a-$ блочная структура спеченной керамики с распределением блоков по размерам; $b$ - типичный вид крупных пор и их распределение по размерам; $c$ - изображение перемычек в поровых каналах (указаны стрелками), на вставке - распределение по размерам мелкой пористости; $d-$ схема блочной структуры с указанием структурных элементов.

\section{Материалы и методы исследования}

Корундовая керамика с многоуровневой поровой структурой была получена аналогично [9]. Образцы имели пористость 50\% и изготавливались методом шликерного литья, в который вводили сферические частицы сверхвысокомолекулярного полиэтилена (СВМПЭ) со средним размером частиц $100 \mu \mathrm{m}$ в количестве $20 \mathrm{vol} . \%$. Спекание керамики осуществлялось на воздухе при температуре $1300^{\circ} \mathrm{C}$ с изотермической выдержкой в течение $1 \mathrm{~h}$.

Спеченные образцы диаметром $10 \mathrm{~mm}$ и высотой $7 \mathrm{~mm}$ подвергали механическим испытаниям на сжатие на универсальной испытательной машине Devotrans при скорости деформации $2 \cdot 10^{-4} \mathrm{~s}^{-1}$. Между пуансонами испытательной машины и поверхностями образцов керамики вкладывались прокладки из алюминиевой фольги для обеспечения равномерной передачи нагрузки на образец.

Для обнаружения на различных стадиях деформирования возможных микро- и макроповреждений были изготовлены образцы с отполированной торцевой поверхностью.

Микроструктуру образцов после спекания и испытаний на сжатие изучали методами оптической и растровой электронной микроскопии (РЭМ). Размер пор в 

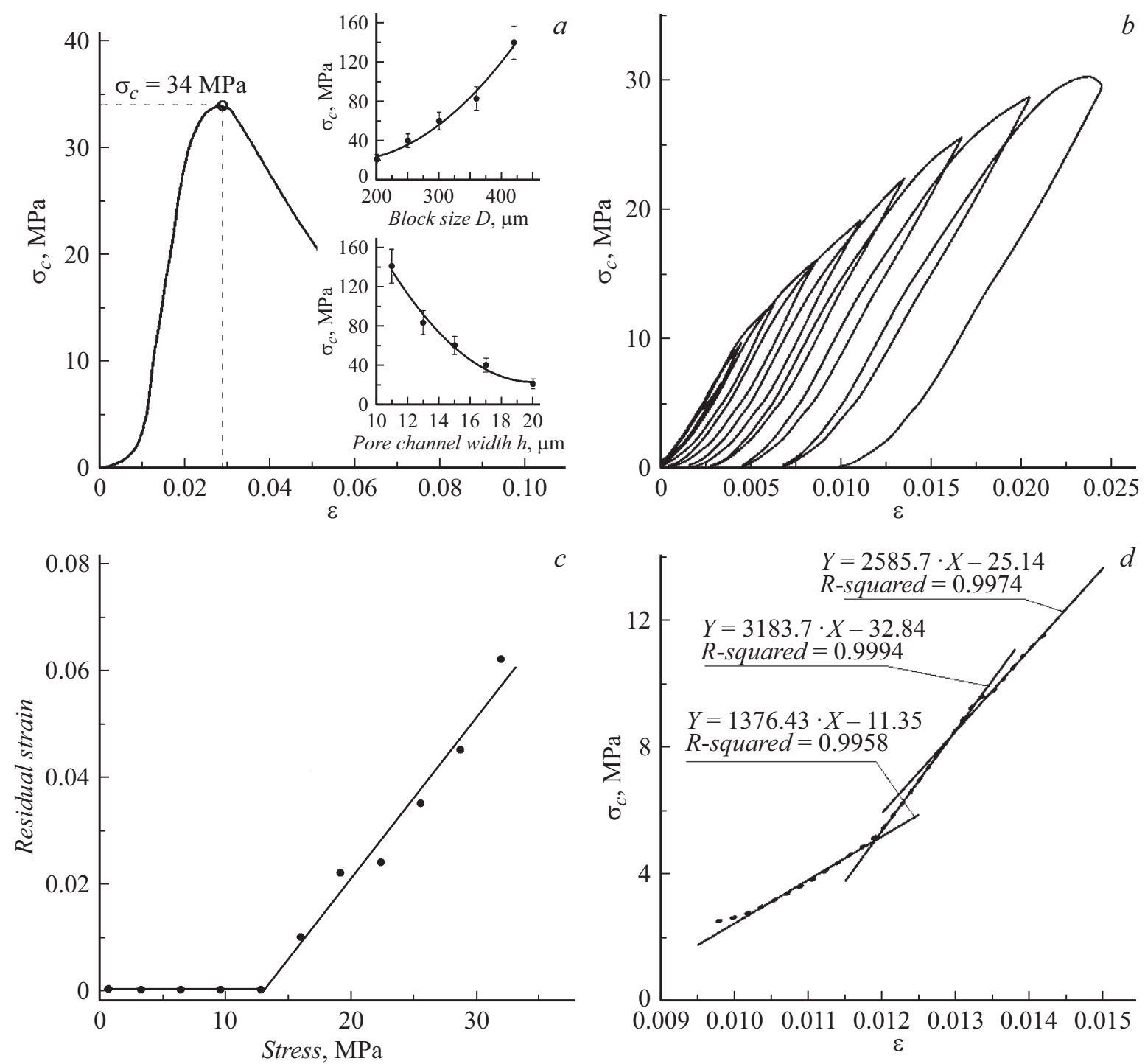

Рис. 2. $a-$ кривая „напряжение-деформация“ керамики до полного разрушения; $b-$ кривые „напряжение-деформация“ керамики при циклической нагрузке с увеличивающейся амплитудой; $c$ - зависимость остаточной деформации в керамике от приложенной максимальной нагрузки; $d$ - детализированная кривая деформирования в области порога пропорциональности.

керамике и расстояние между ними после спекания и после испытаний на сжатие измеряли на приготовленном шлифе по нескольким микроснимкам. Для каждого образца было проведено не менее 400 измерений с получением трехмерного распределения по Салтыкову [10].

\section{Экспериментальные результаты}

Структура спеченной керамики включала в себя три типа пор: мелкие, крупные и промежуточные (рис. 1). Межзеренная мелкая пористость возникала в объеме образца как результат относительно невысокой температуры спекания. Частицы СВМПЭ, являясь порообразователем, способствовали появлению в спеченных образцах керамики крупной пористости. Промежуточная пористость, возникшая в результате эффекта „зонального обособления“ аналогично [9], присутствовала в виде протяженных поровых каналов, соединяющих между собой крупные поры, и формирующих тем самым блочную структуру со средним размером блока порядка $215 \mu \mathrm{m}$ (рис. 1,a). Как видно из рис. 1, $c$, блоки контактируют друг с другом через множество „перемычек“. Средний размер крупных пор составлял порядка $115 \mu \mathrm{m}$ (рис. $1, b)$, а мелкие поры имели средний размер $2.5 \mu \mathrm{m}$ (рис. $1, c)$. Далее на рис. $1, d$ приведена схема блочной структуры с указанием всех структурных элементов. Стоит отметить, что средний размер крупных пор больше, чем средний размер частиц СВМПЭ, и это обусловлено тем, что при добавлении частиц СВМПЭ в шликер происходило их агрегирование, в результате чего в структуре спеченной керамики присутствовали крупные поры, унаследовавшие геометрию как отдельных частиц СВМПЭ, так и их агломератов, размеры которых достигали $500 \mu \mathrm{m}$. 

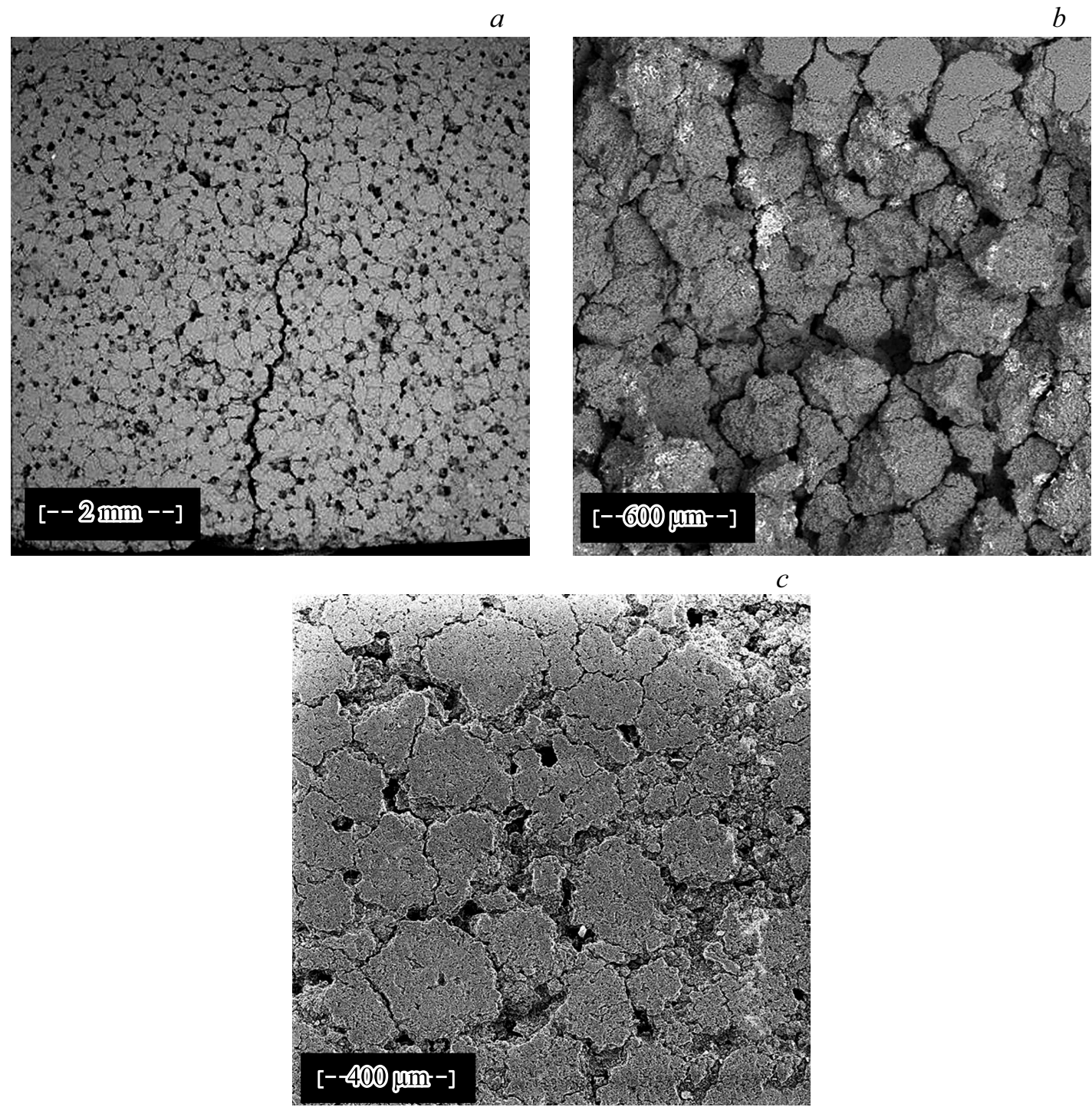

Рис. 3. Изображения РЭМ торцевой полированной поверхности образца после испытаний на сжатия с приложенным напряжением до: $a-\sim 0.3 \times \sigma_{c} ; b-\sim 0.8 \times \sigma_{c} ; c-$ шлиф с поверхности разрушения блочной керамики.

На рис. 2, а показана типичная кривая „напряжение-деформация“ керамики до полного разрушения. Видно, что она имеет сложный характер и по ней невозможно определить начало появления микроразрушений. Тем не менее размеры блоков и ширина поровых каналов существенно влияют на механические свойства спеченной керамики (рис. 2, $a$, вставка). Видно, что прочность растет с увеличением среднего размера блока и уменьшением толщины поровых каналов, которые изменяются в зависимости от температуры спекания ее увеличение приводят к увеличению среднего размера блоков и исчезновению межблочной пористости.

Проведенные циклические испытания для определения начала появления остаточной деформации (предела пропорциональности) (рис. 2, $b, c)$. Как видно из рис. 2,c, остаточная деформация появляется после нагрузки $13 \mathrm{MPa}$. Анализ кривой деформирования в области предела пропорциональности (рис. 2,d) показал, что она может быть разбита на три участка с разным наклоном (разным „техническим“ модулем при сжатии): по-видимому, первый участок соответствует перемещению сформировавшихся при зональном спекании блоков, обусловливая низкий модуль упругости, после разрушения перемычек между ними материал продолжает упруго деформироваться, переходя после $10 \mathrm{MPa}$ нагрузки в „режим“ накопления микроповреждений.

Исследование поверхности образца после нагружения показало, что первые трещины появляются при нагрузке $\sim 0.3 \cdot \sigma_{c}$ (где $\sigma_{c}-$ предел прочности при сжатии), и распространяются по границам между блоками (рис. 3,a). С дальнейшим ростом приложенного напряжения до $\sim 0.8 \sigma_{c}$, практически по всей площади шлифа происходит накопление микроповреждений, приводящее к распространению трещин по границам блоков и выкрашиванию самих блоков (рис. $3, b$ ). 
При исследовании внутренней структуры фрагмента разрушенного материала было обнаружено, что поровые каналы местами значительно шире, чем в исходной структуре (рис. 3, c). Это свидетельствует о локализации деформации в процессе нагружения и движении блоков друг относительно друга, что приводит к выкрашиванию зерен на границах блоков и увеличению расстояния между ними.

\section{Обсуждение полученных результатов}

В литературе известен подход к увеличению вязкости разрушения хрупких материалов, претерпевающих внезапное разрушение из-за трещин, распространяющихся с высокой скоростью, а именно использование блочных, а не монолитных структур [11]. Блоки могут быть скреплены между собой фазой связующего, или благодаря особой геометрии и расположению блоков. При этом слабые границы раздела между блоками обусловливают отклонение распространяющейся трещины с увеличением энергии деформирования без катастрофического разрушения [12].

Исследуемую керамику можно рассматривать как систему со сложной пространственной блочной структурой с ослабленными границами раздела между блоками и наличием перемычек в поровых каналах (рис. $1, c, d)$. При деформации такой керамики наблюдается нелинейность кривых нагружения, которая обусловлена, повидимому, особым деформационным поведением блочной структуры. Вероятно, под нагрузкой перемычки между блоками будут первыми претерпевать разрушение, что приведет к коллапсу поровых каналов между блоками. Результатом такого движения блоков становится увеличение пятна контакта между ними в направлении оси прикладываемого напряжения, и, как следствие, возрастает эффективный модуль упругости всей системы. При этом остаточная деформация появляется только после достаточно высокой нагрузки - около $30 \%$ от предела прочности $\left(\sim 0.3 \cdot \sigma_{c}\right)$, а дальнейшее увеличение нагрузки приводит к накоплению микроповреждений по всему объему образца и катастрофических магистральных трещин не образуется. При достижении $80 \%$ от предела прочности отдельные блоки материала выкрашиваться, но это не оказывает влияния на несущую способность образца в целом. Показательно, что при равных значениях объема порового пространства керамика с многоуровневой поровой структурой показывает более высокие значения предела прочности при сжатии $\left(\sigma_{c} \approx 34 \mathrm{MPa}\right)$ по сравнению с керамикой такого же состава, но с унимодальной пористостью $\left(\sigma_{c} \approx 20 \mathrm{MPa}[4]\right)$.

\section{Заключение}

Показано, что при деформировании керамики с многоуровневой поровой структурой вследствие формиро- вания многочисленных очагов разрушения понижается масштабный уровень разрушения от макроскопического в случае керамики с унимодальной поровой структурой, до мезо- и микромасштабного. При этом вследствие смещения блоков и их групп остаточная деформация в таком материале появляется уже при малых нагрузках - около 30\% от предела прочности.

Показано, что при равных значениях пористости керамика с многоуровневой поровой структурой имеет более высокие значения предела прочности при сжатии по сравнению с керамикой такого же состава, но с унимодальной пористостью.

\section{Благодарности}

Авторы выражают благодарность Н.Л. Савченко за помощь в проведении экспериментов.

\section{Финансирование работы}

Работа выполнена в рамках Программы фундаментальных научных исследований государственных академий наук на 2013-2020 г., раздел III.23 и при частичном финансировании гранта Президента РФ МК-6098.2018.8.

\section{Конфликт интересов}

Авторы заявляют, что у них нет конфликта интересов.

\section{Список литературы}

[1] Ohji T., Fukushima M. // Int. Mater. Rev. 2012. Vol. 57. P. 115-131.

[2] Meille S., Lombardi M., Chevalier J., Montanaro L. // J. Europ. Ceramic Society. 2012. Vol. 32. P. 3959-3967.

[3] Кульков С.Н., Масловский В.И., Буякова С.П., Никитин Д.С. // ЖТФ. 2002. Т. 72. Вып. 3. С. 38-42.

[4] Савченко Н.Л., Саблина Т.Ю., Севостьянова И.Н., Буякова С.П., Кульков С.Н. // ИЗВЕСТИЯ ВУЗОВ. Физика. 2015. № 11. C. 56-60.

[5] Abdur-Rasheed Alao, Ling Yin // J. Mechan. Behavior Biomed. Mater. 2014. Vol. 36. P. 21-31.

[6] Petit C., Meille S., Maire E., Tadier S., Adrien J. // J. Europ. Ceram. Societ. 2016. Vol. 36. P. 3225-3233.

[7] Bruno G., Kachanov M. // J. Europ. Ceram. Societ. 2013. Vol. 33. P. 2073-2085.

[8] Бальшин М.Ю., Кипарисов С.С. Основы порошковой металлургии М.: Металлургия, 1978. 184 с.

[9] Григорьев М.В., Савченко Н.Л., Буякова С.П., Кульков С.Н. // Письма в ЖТФ. 2017. Т. 43. Вып. 15. С. 79-86. DOI: 10.21883/PJTF.2017.15.44874.16652

[10] Салтыков С.A. Стереометрическая металлография М.: Металлургия, 1976. 270 с.

[11] Ghassemi Kakroudi M., Huger M., Gault C., Chotard T. // J. Europ. Ceram. Societ. 2009. Vol. 29. P. 2211-2218.

[12] Carlesso M., Giacomelli R., Krause T., Molotnikov A., Koch D., Kroll S., Tushtev K., Estrin Y., Rezwan K. // J. Europ. Ceram. Societ. 2013. Vol. 33. P. 2549-2558. 